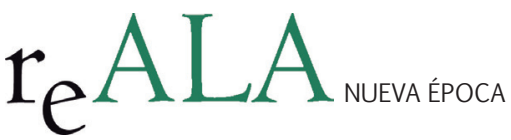

REALA, n 2, julio-diciembre 2014, ISSN: 1989-8975

DOI: http://dx.doi.org/10.24965/reala.voi2.10198

\title{
La integridad del procedimiento de contratación pública en el derecho de la Unión Europea. El conflicto de interés y su incidencia sobre la regulación de las prohibiciones para contratar, las causas de incompatibilidad y las disposiciones sobre transparencia y buen gobierno
}

\author{
Antonio Luis Fernández Mallol \\ Letrado de la Junta de Andalucía. Consejería de Presidencia de la Junta de Andalucía \\ Antonio.fernandez@juntadeandalucia.es
}

Recibido: I 7 de abril 2014 Aceptado: 23 de junio 2014

Resumen

El objetivo de este artículo es contraponer las previsiones relativas a la integridad del procedimiento de contratación que provienen del Derecho Comunitario con el actual régimen previsto en el Texto Refundido de la Ley de Contratos del Sector Público, aprobado mediante el Real Decreto Legislativo 3/2011, de 14 de noviembre (TRLCSP), y determinadas disposiciones relacionadas con la transparencia y buen gobierno que se encentran en fase de elaboración. También persigue realizar una aproximación sobre las implicaciones normativas que conllevan las medidas de las nuevas Directivas sobre contratación pública relativas a transparencia y control de la corrupción, sobre todo en relación con el conflicto de intereses y las conductas ilícitas en este ámbito. Una labor que probablemente permita, además, contribuir a depurar las causas de incompatibilidad, prohibiciones para contratar, y conductas ilícitas en el procedimiento de contratación previsto en el ordenamiento jurídico español.

\section{Palabras clave}

Medidas comunitarias para garantizar una contratación integra. El conflicto de interés en la contratación pública. Prohibiciones para contratar, las causas de incompatibilidad y las disposiciones sobre transparencia y buen gobierno.

\section{The Integrity of the Procurement Procedure in European Union Law. The Conflict of Interest and its Impact on the Regulation of the Prohibitions on Contracting, Causes of Inconsistency and the Provisions on Transparency and Good}

Abstract

This paper aims to compare the provisions regarding the integrity of the procurement procedure of Community law with regard to the current regime provided for in the Consolidated Law on Public Procurement, approved by Royal Legislative Decree 3/2011, of 14 November (TRLCSP), and certain provisions related to transparency and good governance being developed. It also aims to address the regulatory implications of the measures of the new public procurement Directives regarding transparency and corruption control, especially in relation to conflict of interest and illegal activities in this area. This will also probably help to refine the causes of incompatibility, prohibitions on contracting and illegal conduct in the procurement procedure laid down in Spanish law.

\section{Keywords}

Community measures to ensure recruitment integrity. Conflict of interest and illegal conduct in public procurement processes. Prohibitions on contracting, incompatibilities and provisions on transparency and good governance. 
SUMARIO

\begin{abstract}
I. Introducción. II. El conflicto de interés en la contratación pública. La previsión normativa en la nueva directiva de contratos. III. La regulación de las prohibiciones para contratar, las causas de incompatibilidad y las disposiciones sobre transparencia y buen gobierno como medidas insuficientes para garantizar la moralidad administrativa. IV. Conclusiones.
\end{abstract}

\title{
1․- INTRODUCCIÓN
}

El objetivo de este artículo es contraponer las previsiones relativas a la integridad del procedimiento de contratación que provienen del Derecho de la Unión Europea con el actual régimen previsto en el Texto Refundido de la Ley de Contratos del Sector Público, aprobado mediante el Real Decreto Legislativo 3/2011, de 14 de noviembre (TRLCSP), y determinadas disposiciones relacionadas con la transparencia y buen gobierno que se encuentran en fase de elaboración ${ }^{1 . ~ T a m b i e ́ n ~ p e r s i g u e ~ r e a l i z a r ~ u n a ~ a p r o x i m a c i o ́ n ~ s o b r e ~ l a s ~ i m p l i c a c i o n e s ~ n o r m a t i v a s ~ q u e ~}$ conllevan las medidas de las nuevas Directivas ${ }^{2}$ sobre contratación pública relativas a transparencia y control de la corrupción, sobre todo en relación con el conflicto de intereses y las conductas ilícitas en este ámbito. Una labor que probablemente permita, además, contribuir a depurar las causas de incompatibilidad, prohibiciones para contratar, y conductas ilícitas en el procedimiento de contratación previsto en el ordenamiento jurídico español.

La contratación pública desempeña un papel clave en la Estrategia Europa 2020 como uno de los instrumentos esenciales para lograr el desarrollo de una economía competitiva con alto nivel de empleo, basada en el conocimiento y la innovación, el uso más eficaz de los recursos y la cohesión social y territorial.

Por ello, la Exposición de Motivos de la Propuesta de Directiva del Parlamento Europeo y del Consejo relativa a la contratación pública de 20 de diciembre de 2011 (PDCP), proponía una revisión de la legislación contractual vigente y establecía como objetivos a conseguir; incrementar la eficiencia del gasto público y permitir que los compradores utilicen mejor la contratación en apoyo de objetivos sociales comunes.

En este contexto, se han promulgado las nuevas Directivas sobre contratación pública: la Directiva 2014/23/UE del Parlamento Europeo y del Consejo, de 26 de febrero de 2014, relativa a la adjudicación de contratos de concesión; la Directiva 2014/24/UE del Parlamento Europeo y del Consejo, de 26 de febrero de 2014, sobre contratación pública y por la que se deroga la Directiva 2004/18/CE y la Directiva 2014/25/UE del Parlamento Europeo y del Consejo, de 26 de febrero de 2014, relativa a la contratación por entidades que operan en los sectores del agua, la energía, los transportes y los servicios postales y por la que se deroga la Directiva 2004/17/CE.

Resulta innegable que, con independencia de las sensibles modificaciones que ha sufrido la propuesta de Directiva de contratación en el proceso legislativo hasta su versión definitiva, las medidas contra la corrupción administrativa son los pilares básicos sobre los que se van a articular las disposiciones fundamentales en materia de contratación durante los próximos años, perfiladas de una u otra manera, para lograr combatir las conductas deshonestas y el favoritismo en el seno de la Unión Europea.

En un plano diferente, en nuestro ordenamiento jurídico, casi de forma coetánea al nacimiento de la crisis económica, se han venido elaborando planteamientos y disposiciones legales que pretenden, en gran medida, aumentar la transparencia y la integridad de la contratación pública como mecanismo más efectivo contra la corrupción. Esta batería normativa ansía reforzar los mecanismos de información y transparencia que ya existen en el ordenamiento jurídico potenciando la transparencia y el buen gobierno. ${ }^{3}$

1 Me refiero a las disposiciones en materia de transparencia y buen gobierno que se encuentran en la mayoría de los casos en fase de elaboración y que inciden sobre la contratación pública. Podemos citar, en el ámbito estatal, la recién aprobada Ley19/2013, de 9 de diciembre, de Transparencia, Acceso a la Información Pública y Buen Gobierno, que en principio, surge como una medida fundamental para garantizar la igualdad y equidad en el tratamiento de la información y la distribución de los recursos públicos. En otros ámbitos cabe mencionar la Ley 4/2006, de 30 de junio, de Transparencia y Buenas Prácticas de la Administración Pública Gallega, el Anteproyecto de Ley de Transparencia Pública de Andalucía, aprobado por el Consejo de Gobierno el 4 de junio de 2013 y la Ley 4/2011, de 31 de marzo, de la Buena Administración y del Buen Gobierno de las Illes Balears.

2 Se trata de la Directiva 2014/23/UE del Parlamento Europeo y del Consejo, de 26 de febrero de 2014, relativa a la adjudicación de contratos de concesión; la Directiva 2014/24/UE del Parlamento Europeo y del Consejo, de 26 de febrero de 2014, sobre contratación pública y por la que se deroga la Directiva 2004/18/CE y la Directiva 2014/25/UE del Parlamento Europeo y del Consejo, de 26 de febrero de 2014 , relativa a la contratación por entidades que operan en los sectores del agua, la energía, los transportes y los servicios postales y por la que se deroga la Directiva 2004/17/CE.

3 Sobre la naturaleza de estas nuevas disposiciones pueden consultarse los trabajos de ALVAREZ MARTín, J.A. "La futura ley de transparencia ¿una solución adecuada y creíble?” Revista Aranzadi Doctrinal número 7/2012 o, con una concepción más positiva de la norma, el trabajo de GARCIA TORRES, A. "Transparencia.-Acceso a la Información Pública.-Buen Gobierno. Proyecto de Ley de Transparencia, Acceso a la Información Pública y buen Gobierno”, La Administración Práctica, número 9/2012. 
El análisis de las previsiones europeas que se avecinan y su contraposición con la modificación normativa que se está produciendo en el ordenamiento español puede destapar graves distorsiones, aventurar modificaciones importantes y descubrir, en algunos casos, medidas insuficientes para un objetivo tan necesario y complejo.

En consecuencia, sin llegar a los términos expresados por SANTAMARIA PASTOR cuando califica la normativa comunitaria de contratación pública como "un desastre sin paliativos", lo cierto es que el resultado de la interacción de los distintos poderes legislativos es un producto manifiestamente mejorable.

\section{$2^{\circ}$ - EL CONFLICTO DE INTERÉS EN LA CONTRATACIÓN PÚBLICA. LA PREVISIÓN NORMATIVA EN LA NUEVA DIRECTIVA DE CONTRATOS}

Resulta pacífico admitir que el ordenamiento jurídico español no ha logrado articular, desde una perspectiva técnica, disposiciones ni mecanismos que eviten los conflictos de interés o que garanticen la imparcialidad de forma sólida, no sólo en el ámbito de la contratación, sino también en otros sectores de la actividad pública. Puede que la previsión plasmada en el artículo 24 de la Propuesta de Directiva de Contratación Pública, aprobada por el Parlamento Europeo el 15 de enero de 2014, y la interpretación que ofrezca el TJUE sean herramientas novedosas muy útiles para alcanzar una madurez en un sector atrapado en una minoría de edad forzosa. Quizás sean elementos fundamentales para elevar la maltrecha moralidad administrativa que, probablemente, hayan tenido en los incidentes de recusación del Presidente del Tribunal Constitucional por falta de imparcialidad, uno de sus máximos exponentes en la actual democracia. ${ }^{5}$

Sin ánimo exhaustivo, y sin desconocer que existen otras causas de distinta índole, es evidente que existen factores normativos evidentes y palpables que contribuyen a perturbar la integridad del procedimiento en aspectos que son de difícil justificación ante el ciudadano. $1^{\circ}$ ) El primer motivo, que obedece a la propia actuación comunitaria, atiende al diseño e incidencia de la normativa europea y la sinergia con los Estados miembros ${ }^{6}$. Efectivamente, es difícil explicar a un ciudadano que la normativa europea en materia de contratación sólo se aplica, en la mayoría de los casos, para contratos que superen determinados umbrales fijados arbitrariamente. ${ }^{7}$ Es muy complicado, argumentar porqué los contratos de menor cuantía, que en la práctica son la mayoría, están exentos de las mayores garantías de control e imparcialidad8. También es difícil justificar porque los Estados miembros han incumplido sistemáticamente la normativa contractual?.

$2^{\circ}$ ) El principal ataque a la integridad deriva de la diversidad de regímenes de incompatibilidad y conflictos de interés que recoge la normativa administrativa. Una diferencia que no sólo se refiere a la distinción que puede producirse entre quienes dirigen entes instrumentales y Administraciones territoriales, que en la práctica, en materia de contratación, ya es de por sí muy significativa, sino que el régimen de incompatibilidades y el tratamiento del conflicto de interés es diferente también según cuál sea la Administración correspondiente. Realidad que no encuentra justificación posible.

$3^{\circ}$ ) Finalmente el tercer eje del desafortunado panorama actual deriva de la propia acción legislativa en lamateria y la consciente falta de medios de control. La relación entre las causas de incompatibilidad, los conflictos de interés y la imparcialidad en la actividad administrativa es una materia conocida, pero sobre la que poco se ha lucido el legislador en todas las instancias normativas.

4 SANTAMARIA PASTOR, J.A. "La constante e interminable reforma de la normativa sobre contratación pública" Revista Española de Derecho Administrativo, número 159, página 32.

5 Sobre este episodio, resulta muy interesante el artículo de GUAJARDo PÉREZ, I. “Afiliación política de los Magistrados del Tribunal Constitucional. Inadmisión de la recusación promovida contra su Presidente por el parlamento y la Generalidad de Cataluña (artículo 219 LOPJ núms. 9 y 10)" Diario La Ley, n 8198, 25 de noviembre de 2013, edit. La Ley.

6 En esta línea debe citarse el trabajo de J.A. MOLINA, “Un mundo para SARA, una nueva categoría en el Derecho español de la contratación pública, los contratos sujetos a regulación armonizada" Revista de Administración Pública, número 178, 2009 , páginas 175 a 213.

7 La nueva Directiva de contratos públicos, se aplicara según el artículo 4, a las contrataciones cuyo valor estimado, sin incluir el impuesto sobre el valor añadido (IVA), sea igual o superior a los umbrales siguientes: (a) 5186 ooo EUR, en los contratos públicos de obras; (b) 134000 EUR, en los contratos públicos de suministro y de servicios adjudicados por autoridades gubernamentales centrales y los concursos de proyectos organizados por ellas; por lo que se refiere a los contratos públicos de suministro adjudicados por poderes adjudicadores que operen en el sector de la defensa, ese umbral solo se aplicará a los contratos relativos a los productos contemplados en el anexo III; (c) 207 ooo EUR, en los contratos públicos de suministro y de servicios adjudicados por poderes adjudicadores subcentrales y los concursos de proyectos organizados por los mismos; (d) 750000 EUR, en los contratos públicos de servicios sociales y otros servicios específicos enumerados en el anexo XIV.

8 Esta tendencia se constata en la Memoria del Tribunal de Cuentas del año 2011, aprobada por el Pleno el 26 de abril de 2012 donde se evidencia la falta de justificación del procedimiento negociado en el procedimiento de contratación. Igualmente el Informe sobre el total de los contratos celebrados por las entidades adjudicadoras en el año 2011, elaborado por el Registro Público de Contratos dependiente del Ministerio de Economía y Hacienda, revela que el 47,85\% de los contratos se adjudica a través del procedimiento negociado.

9 Se trata de las siguientes resoluciones judiciales: STJE de 15 de mayo de 2003 (RJ 2003,168) STJE de 16 de octubre de 2003 (RJ 2003,329), STJE de 13 de enero de 2005 (RJ 2005,10) y STJE de 3 de abril de 2008 (RJ 2008,59). 
Descendiendo en el tratamiento del conflicto de interés en la contratación pública parece interesante contraponer la previsión de la nueva disposición de referencia comunitaria, la Directiva 2014/24/UE del Parlamento Europeo y del Consejo, de 26 de febrero de 2014 sobre contratación pública, en relación con el contenido de las nuevas normas sobre transparencia.

Analicemos la previsión normativa. Señala el artículo 24 de la Directiva que:

"Los Estados miembros velarán para que los poderes adjudicadores tomen las medidas adecuadas para prevenir, detectar y solucionar de modo efectivo los conflictos de intereses que puedan surgir en los procedimientos de contratación a fin de evitar cualquier falseamiento de la competencia y garantizar la igualdad de trato de todos los operadores económicos.

El concepto de conflicto de intereses comprenderá al menos cualquier situación en la que los miembros del personal del poder adjudicador, o de un proveedor de servicios de contratación que actúe en nombre del poder adjudicador, que participen en el desarrollo del procedimiento de contratación o puedan influir en el resultado de dicho procedimiento tengan, directa o indirectamente, un interés financiero, económico o personal que pudiera parecer que compromete su imparcialidad e independencia en el contexto del procedimiento de contratación."

En consecuencia el contenido del artículo obliga a los Estados miembros a que adopten medidas para prevenir, detectar y solucionar de inmediato los conflictos de intereses que puedan surgir en todas las fases de los procedimientos de contratación a fin de evitar cualquier falseamiento de la competencia y garantizar la igualdad de trato de todos los licitadores. Además, incorpora, un concepto amplio y ambicioso de qué intereses concurrentes deben entenderse prohibidos en el procedimiento de licitación ${ }^{10}$. Concretamente el concepto de conflicto de interés que recoge el artículo 24 exige, como mínimo, la concurrencia de una doble condición:

A) Condición subjetiva. Quedan afectados los miembros del personal del poder adjudicador, proveedores de servicios de contratación o miembros del personal de otros proveedores de servicios que participen en el desarrollo del procedimiento de contratación ${ }^{11 .}$

Nótese que la previsión incide con la misma rigidez de forma vertical y horizontal. En el primer caso, la disposición afecta a la conducta del dirigente o dirigentes que participen en el ente, como también respecto a cualquier empleado del ente adjudicador o del contratista. Horizontalmente, la limitación condiciona el comportamiento de los sujetos que intervengan directa e indirectamente en el procedimiento de contratación ya sean del ente adjudicador, como proveedor o como responsable de alguna entidad interesada que pueda falsear las condiciones de licitación,

B) Condición objetiva. Afecta a cualquier situación en la que directa o indirectamente concurra un interés particular en el resultado del procedimiento de contratación, que pueda percibirse como un impedimento para la ejecución imparcial y objetiva de sus funciones. Concretamente la disposición se refiere a intereses financieros, económicos o personales que pudieran limitar la imparcialidad e independencia en el contexto del procedimiento de contratación.

El texto adoptado en el Parlamento Europeo limita la dicción originaria de la Propuesta de Directiva, que utilizaba una enumeración extensa de eventuales intereses concurrentes, incluso con una cláusula analógica. No obstante entendemos que el espíritu de la norma debe obligar a que los Estado miembros prohíban, en la transposición de la Directiva, cualquier eventual situación que pueda interferir en la imparcialidad de los sujetos que intervienen en el procedimiento de contratación. No es admisible que situaciones en las que pueden coexistir intereses profesionales, familiares o afectivos puedan quedar excluidas de la regulación que realicen los Estados miembros permitiendo resquicios legales que conculquen la integridad del procedimiento de contratación.

En la jurisprudencia del TJUE no existen muchos pronunciamientos sobre la aplicación de las normas europeas y los conflictos de interés. Salvo error, solamente hemos encontrado dos pronunciamientos. En la STJUE de 16

10 La realidad es que el texto definitivo de la nueva Directiva de contratos adoptado por el Parlamento Europea ha eliminado un gran número de disposiciones del proyecto inicial orientadas en garantizar la integridad del procedimiento (las denominadas conductas ilícitas en la contratación pública y la nueva gobernanza en materia de contratación pública) y se ha centrado en introducir novedades en relación con el procedimiento electrónico y la gestión de la información.

11 La redacción de la propuesta de Directiva remitida al Parlamento era más ambiciosa y recogía una referencia al “presidente del poder adjudicador y los miembros de sus órganos decisorios que, sin intervenir necesariamente en el desarrollo del procedimiento de contratación, podrían no obstante influir en su resultado" como muestra de voluntad tajante de extender las causas de conflicto a los dirigentes políticos que participen en la gestión del ente de contratación. 
de diciembre 2008, en el asunto Michaniki, (recurso C-213/2007), el Tribunal recalca que el Derecho comunitario debe interpretarse en el sentido de que se opone a una disposición nacional que, en aras de la consecución de los objetivos legítimos de igualdad de trato entre los licitadores y de transparencia en los procedimientos de adjudicación de los contratos públicos, establezca una presunción absoluta de incompatibilidad en dos sectores distintos ${ }^{12 .}$ Por su parte la STJUE de 6 de mayo de 2010 en el asunto Club Hotel Loutraki AE y otros contra Ethniko Symvoulio Radiotileorasis y otros, (recurso C-145/08 y C-149/08), se analiza el eventual conflicto de interés en una Unión Temporal de Empresas cuando una de ellas decide accionar y no existe voluntad de todas. ${ }^{3}$ No obstante, la función del TJUE será esencial para garantizar la aplicación de la norma comunitaria asegurando una interpretación útil de la misma que permita garantizar la integridad de la contratación pública.

Conectado con esta última apreciación, la necesidad de adoptar medidas que garanticen la utilidad de la prohibición del conflicto de interés, resulta conveniente ahondar en la naturaleza totalmente perversa que generan estas situaciones en el procedimiento de contratación. Una realidad que el Derecho de la Unión Europea no puede desconocer.

Actualmente resulta indudable la incidencia directa de la contratación pública en relación con los resultados macroeconómicos de los Estados miembros y con las formas de distribución de la riqueza ${ }^{14}$. Es innegable que existe un binomio, admitido en el actual contexto, entre el éxito empresarial y las adjudicaciones públicas que la empresa haya podido disfrutar. Por otra parte, casi de forma paralela, también es conocido que el círculo de contratación pública se cierra con el nexo de unión entre el empresario y la entidad pública. Una vinculación que debe sujetarse a los principios de eficiencia y oferta más ventajosa, según los artículos 22 y 150 del TRLCSP, pero que, en la realidad, se ciñe principalmente a un conocimiento previo, la relación de confianza o un interés compartido como elementos determinantes.

Precisamente, es a partir de ese momento, en el que se articula la conexión artificial entre contratista y entidad pública sobre parámetros inadecuados, cuando comienzan los principales vicios del procedimiento de contratación; el clientelismo, la desigualdad de oportunidades, la falta de transparencia, la conculcación de la libre concurrencia o la ineficiencia del contrato, aparecen como fracturas de la integridad del procedimiento de contratación pública. Probablemente sea esta vinculación ajena a los criterios marcados por la norma, la principal causa de frustración del procedimiento de contratación pública.

Planteado el debate en estos términos, a nuestro juicio, quizá la medida esencial para reflotar la integridad del procedimiento de contratación sea reforzar la vinculación del contratista y el ente público a través de la eficiencia y la oferta más ventajosa, desplazando los eventuales intereses concurrentes que puedan converger. Ésa es la pieza básica y angular para garantizar la integridad. Eliminar y arrinconar las rentas ilícitas que puedan surgir a los participantes en procedimiento de contratación.

Efectivamente, al margen de cualquier norma adjetiva de información y transparencia, la situación actual exige alzar los límites de la moralidad administrativa como parámetro de referencia para prohibir determinadas conductas que vician la contratación pública y, por supuesto, la actividad administrativa. Eliminar los ámbitos de exención o la impunidad de determinados comportamientos es la única vía para reconducir unas prácticas crónicas y enfermizas que atentan contra el sistema en su conjunto. En definitiva, cualquier planteamiento que pretenda alterar mínimamente la realidad debe partir de la necesidad de eliminar los eventuales conflictos de interés que puedan concurrir.

No basta con adoptar decisiones que obliguen a obtener eficiencia y rentabilidad en la contratación pública, el ordenamiento jurídico debe, además, eliminar situaciones donde puedan concurrir intereses concurrentes. No

12 La Sentencia rechaza una disposición que establezca un eventual conflicto de intereses per se cuando se trata de entidades que operan en sectores diferenciados. Concretamente el TJUE critica que se presuma el conflicto entre quien ostenta la condición de propietario, socio, accionista principal o directivo de una empresa activa en un sector específico de los medios de comunicación y la condición de propietario, socio, accionista principal o directivo de una empresa a la que el Estado o una persona jurídica del sector público en sentido amplio confía la ejecución de contratos de obras, suministros o servicios

13 En esta Sentencia prima la tutela judicial al eventual conflicto de intereses, declarando el Tribunal que el Derecho de la Unión, en particular el derecho a una tutela judicial efectiva, se opone a una normativa nacional, como la cuestionada en el litigio principal, que se interpreta en el sentido de que los miembros de una unión temporal de empresas, licitadora en un procedimiento de adjudicación de un contrato público, sean privados de la posibilidad de solicitar, a título individual, la reparación del perjuicio que hayan sufrido de forma individual a raíz de una resolución, adoptada por una autoridad distinta del poder adjudicador, que forme parte de dicho procedimiento de conformidad con las normas nacionales aplicables, y que pueda influir en su desarrollo.

14 Como datos significativos podemos señalar que, según la guía de contratación pública del Ministerio de Industria, Energía y Turismo la contratación pública en el año 2010 supuso 130.000 millones de euros, lo que supone un aproximadamente un 13\% el Producto Interior Bruto del Estado. También es muy ilustrativo que, según el Observatorio de Contratación Pública, en torno a un 3\% de esta cifra se utilizó inadecuadamente por una conculcación de las normas de contratación pública. 
es suficiente una regulación parcial de la materia, resulta imprescindible disposiciones minuciosas, completas y aplicables a todos los entes del sector público como medida normativa imprescindible para eliminar los eventuales conflictos de interés en la contratación pública. Junto con ello, es necesario, para garantizar la moralidad administrativa, perfilar preceptos en los términos que se expondrán. Pero, qué duda cabe, la situación actual exige una batería de medidas de otra naturaleza. ${ }^{15}$ Es imprescindible reforzar los mecanismos de control existentes y, además crear otros nuevos. ${ }^{16}$ Los medios de control preventivos son los instrumentos más necesarios y eficaces, con una utilidad directa sobre la seguridad en el tráfico jurídico y un poder conformador de la sociedad de un valor incalculable.

En definitiva, socialmente sólo es admisible el control preventivo que evite o impida la realización del ilícito, porque, cuando la irregularidad está consumada y no existe posibilidad de restituir la situación anterior, la sensación de justicia desaparece generando el desconsuelo ciudadano

Por todo ello, la previsión comunitaria sobre la interdicción del conflicto de interés en la contratación pública debe suponer una oportunidad para los Estados miembros de promover, verdaderamente, una contratación pública integra. Igualmente esta previsión debe conllevar, necesariamente, elevar la maltrecha moralidad administrativa en la contratación pública española perfilando disposiciones y adoptando medidas complementarias que aseguren espacios de imparcialidad y objetividad para lograr la consecución del interés general.

\section{LA REGULACIÓN DE LAS PROHIBICIONES PARA CONTRATAR, LAS CAUSAS DE INCOMPATIBILIDAD Y LAS DISPOSICIONES SOBRE TRANSPARENCIA Y BUEN GOBIERNO COMO MEDIDAS INSUFICIENTES PARA GARANTIZAR LA MORALIDAD ADMINISTRATIVA}

A nuestro juicio, la actual concepción europea del conflicto de interés obliga a modificar determinadas disposiciones del ordenamiento interno español, con la finalidad de contribuir a garantizar verdaderos ámbitos de imparcialidad y moralidad en la contratación pública. Modificaciones que deben trascender del tenor literal del artículo 24 de la Directiva 2014/24/UE del Parlamento Europeo y del Consejo, de 26 de febrero de 2014 sobre contratación pública, y centrarse, de forma más ambiciosa, en el espíritu de la norma informando, de esta manera, las distintas interpretaciones de los órganos consultivos en relación con prácticas discutibles en el seno de la contratación pública.

No cabe duda que si, finalmente, se incorporan al ordenamiento jurídico español las previsiones relativas a los conflictos de interés en unos términos tan amplios, con referencias a intereses directos o potenciales de empleados públicos o políticos, en relación incluso a intereses "compartidos", pueden eliminarse las distorsiones normativas hirientes que existían hasta la fecha. Más aún cuando las conductas ilícitas de la contratación previstas en la norma quizás lleguen a ser una herramienta adicional útil para impedir la corrupción en este ámbito.

Analicemos las principales distorsiones normativas y procedimentales que existen en la contratación pública actual.

\section{$1^{\text {a }}$ DISTORSIÓN: LAS PROHIBICIONES PARA CONTRATAR Y CAUSAS DE INCOMPATIBILIDAD}

La prohibiciones para contratar son circunstancias heterogéneas que impiden la celebración de contratos con el sector público porque en ellas subyace o albergan dudas sobre la honorabilidad del contratista, o bien, posibles conflictos de interés que aconsejan limitar la contratación con los sujetos en quien concurre con el objetivo de garantizar la objetividad y la imparcialidad en la contratación pública. ${ }^{17}$

En consecuencia, es el ámbito natural en el que deben incidir las nuevas medidas para garantizar la integridad del procedimiento de contratación ${ }^{18}$

Si se examinan la variedad de situaciones que se contemplan en cada una de las prohibiciones de contratar se advierte que el fundamento de las mismas, fuera de la genérica protección del interés público es muy diverso y ha variado con el tiempo ${ }^{19}$.En algunas ocasiones se trata de circunstancias relacionadas con la falta de honorabilidad

15 Así se extrae de numerosos Informes Internacionales, pudiendo citar el Informe de transparencia Internacional o el de la OCDE de 2011, vid. "La integridad en la contratación pública, buenas prácticas de la A a la Z”, traducción del libro Integrity in public procurement. God practice to $A$ to $Z$. edit. OCDE, París, p. 35.

16 En este sentido se manifiesta MEDINA ARNAIZ,T., al exigir un órgano externo que vigile y controle la aplicación de las normas de contratación como una medida indispensable para la lucha contra la corrupción ("Las respuestas normativas al fenómeno de la corrupción en la contratación pública”, Diario La Ley número 7832, sección doctrina, de 16 de abril de 2010.

17 Sobre las prohibiciones para contratar con las entidades del sector público en el ordenamiento jurídico español resulta muy ilustrativa la obra de J. BESTEIRO RIVAS, Comentario al artículo 49 LCSP: Las Prohibiciones de contratar, edit. Aranzadi, Pamplona 2009.

18 I. GALLEGO CóRCOLES, “Prohibiciones de contratar: el régimen de incompatibilidades (I)" Contratación Administrativa Práctica: Revista de la Contratación Administrativa y de los Contratistas n 40/2005, edit. La Ley, Madrid, 2005, página. 54.

19 Realmente, si se examina la evolución de la legislación en materia de contratación de las Administraciones Públicas, lo primero que 
del licitador, como sería el supuesto previsto en el artículo 60.1.a); en otras ocasiones se trata de supuestos en los que el fundamento se encuentra en el rechazo que generan que contraten con la Administración Pública aquéllos que no cumplen sus deberes como ciudadanos; este sería el caso de los dispuesto en el apartado 60.1.d), mientras que otras ocasiones el motivo de la prohibición obedece a tratar de garantizar la objetividad de la Administración Pública en situaciones de conflictos de interés, ejemplo de lo cual sería el apartado 60.1.f).20 En definitiva, con las prohibiciones para contratar se pretende garantizar que no va a existir ningún elemento que distorsione la contratación del sector público a la hora de gestionar los intereses generales.

Precisando esta cuestión, un sector de la doctrina, a la luz de distintos pronunciamientos judiciales, ha concretado que el fundamento de estas prohibiciones para contratar se encuentra en la necesidad de preservar "Ia moralidad administrativa" a la hora de contratar las Administraciones Públicas. Un origen que deriva necesariamente de lo dispuesto en el artículo 103 CE. ${ }^{21}$

Se trata de causas que además, tradicionalmente, se han vinculado a los instrumentos legales para garantizar la transparencia en la contratación pública y por ello, el actual precepto que las recoge, el artículo 60 TRLCSP, ha sido ya objeto de diversas modificaciones. ${ }^{22}$

Pues bien, la previsión normativa del conflicto de interés que proviene de Europa exigiría, a nuestro juicio, una nueva formulación de algunas de las circunstancias previstas en el artículo 60 TRLCSP, a fin de lograr cumplir los objetivos comunitarios. Concretamente entendemos que deben perfilarse las circunstancias previstas en el apartado f) y g) como prohibiciones cuya misión principal es evitar los eventuales conflictos de interés que pueda concurrir. Circunstancias que pasamos a estudiar.

\section{Incompatibilidad de altos cargos y funcionarios}

Establece el apartado $\mathrm{f}$ del artículo 60.1 TRLCSP que no podrán contratar con el sector público las personas en quienes concurran alguna de las circunstancias siguientes:

f) Estar incursa la persona física o los administradores de la persona jurídica en alguno de los supuestos de la Ley 5/2006, de 10 de abril, de Regulación de los Conflictos de Intereses de los Miembros del Gobierno y de los Altos Cargos de la Administración General del Estado, de la Ley 53/1984, de 26 de diciembre, de Incompatibilidades del Personal al Servicio de las Administraciones públicas o tratarse de cualquiera de los cargos electivos regulados en la Ley Orgánica 5/1985, de 19 de junio, del Régimen Electoral General, en los términos establecidos en la misma. La prohibición alcanzará a las personas jurídicas en cuyo capital participen, en los términos y cuantías establecidas en la legislación citada, el personal y los altos cargos de cualquier Administración Pública, así como los cargos electos al servicio de las mismas. La prohibición se extiende igualmente, en ambos casos, a los cónyuges, personas vinculadas con análoga relación de convivencia afectiva y descendientes de las personas a que se refieren los párrafos anteriores, siempre que, respecto de los últimos, dichas personas ostenten su representación legal."

Esta circunstancia probablemente deba ser la primera disposición que debe definirse nuevamente tras la futura regulación comunitaria y ello pese a que, hasta la fecha, ya ha generado bastante literatura jurídica. ${ }^{23} \mathrm{Ha}$

se advierte es que la relación de prohibiciones para contratar ha ido creciendo progresivamente desde la Ley de Administración y Contabilidad de 1 de julio de 1911 (que no contenía una lista de prohibiciones). El Reglamento de Contratos de las Corporaciones Locales de 9 de enero de 1953 ya incluía una lista con seis prohibiciones (más una previsión de incompatibilidad regulada en un artículo distinto), que posteriormente se incrementó a ocho supuestos en la redacción originaria del texto articulado de la Ley de Contratos del Estado. Con la reforma operada por el Real Decreto legislativo 931/1986 de 2 de mayo esta lista aumentó hasta alcanzar los diez supuestos de prohibición para contratar hasta llegar a los once casos previstos en el artículo 20 del TRLCAP. La Ley 30/2007, de 30 de octubre, de Contratos del Sector Público introdujo una modificación en este sentido. Recogió en el artículo 49 LCSP los doce apartados que expresan las prohibiciones para contratar con los entes del sector público, distinguiendo siete circunstancias comunes a todos los contratistas que pretendan con los entes del sector público, y cinco causas que afectan exclusivamente a los licitadores de las Administraciones Públicas. La Ley introdujo variaciones, como posteriormente veremos, pero no ha logrado solventar los principales problemas apreciados bajo la vigencia de la normativa anterior El actual TRLCSP se refiere a ellas en el artículo 60 TRLCSP.

20 El artículo 60.1.a) se refiere a la prohibición de contratar de aquellos que hayan sido condenados por determinados delitos. El artículo 60.1.d) recoge la prohibición para contratar de quien no estar al corriente de sus obligaciones con Hacienda y la Seguridad Social y el articulo 60.1.f) es el que versa sobre las causas de incompatibilidad como determinantes de prohibiciones para contratar.

21 Este parecer se extrae no solo de los informes de los órganos consultivos sino también de los distintos pronunciamientos judiciales existentes en este ámbito, pudiendo citar las Sentencias del Tribunal Supremo de 17 de febrero de 1992 (RJ 1992, 2491), la Sentencia de 24 de noviembre de 2004 (RJ 2004,8061) Sentencia de 4 de octubre de 2005 (RJ 2005, 8752) o la Sentencia del Tribunal Supremo de 30 de enero de $2007(2007,830)$.

22 Antes de su plasmación en el TRLCSP el contenido del artículo 60 ha sido modificado por el Real Decreto Ley 5/2011, de 29 de septiembre, la Ley 34/2010, de 5 de agosto y el Real Decreto 6/2010 de 6 de abril de 2010. Modificaciones sintomáticas de la transcendencia del precepto y de las deficiencias de la técnica normativa empleada.

23 En esta materia resulta de interés en relación con el artículo 20 TRLCAP el análisis de I. GALLEGO cóRCOLES, “Prohibiciones de contratar. El régimen de incompatibilidades (II)" Contratación Administrativa Práctica: Revista de la Contratación Administrativa y de los Contratistas n 41/2005, edit. La Ley, Madrid, 2005. 
sido una circunstancia que ha planteado dudas muy diversas ${ }^{24}$, pero el núcleo se ciñe a las limitaciones de cargos electos, sobre todo en la Administración Local, y en relación con las incompatibilidades aplicables a funcionarios públicos.

En concreto se han planteado distintas dudas sobre la interpretación que debían darse al apartado equivalente previsto en el extinto artículo 20 TRLCAP y su relación con la Ley 5/2006, de 10 de abril, de Regulación de los Conflictos de Intereses de los Miembros del Gobierno y de los Altos Cargos de la Administración General del Estado, la Ley 53/1984, de 26 de diciembre, de Incompatibilidades del Personal al Servicio de las Administraciones Públicas y lo dispuesto en la Ley Orgánica 5/1985, de 19 de junio del Régimen Electoral General. La problemática que se planteaba surgía de la remisión que realizaba la normativa contractual al régimen de incompatibilidades de los Altos Cargos, cargos electos de las entidades locales y a la normativa equivalente de los funcionarios públicos. Dificultad que se acrecentaba por el distinto régimen de incompatibilidad previsto en una y otra normativa y la necesidad de lograr una salvaguarda de los principios de contratación pública.

Con el actual artículo 60 TRLCSP todavía se han planteado dudas a este respecto, si bien el cuerpo principal de problemas parece tener una interpretación común.

Las conclusiones a las que han llegado los distintos informes y dictámenes podemos sintetizarlas de la siguiente forma:

El Informe 50/99, de 21 de diciembre de 1999, de la Junta Consultiva de Contratación Administrativa (JCCA) o el Informe 30/2010, de 24 de noviembre de 2010, del mismo órgano consultivo, ponen de manifiesto que la norma de la que hay que partir para determinar la incompatibilidad de los cargos electos de las Corporaciones Locales con la actividad contractual del sector público es la disposición reguladora de las prohibiciones de contratar, en el caso que nos ocupa el artículo 60.1, letra f), de TRLCSP, y, dentro de ella, para los concejales, el artículo 178 de la Ley Orgánica 5/1985, de 19 de junio, de Régimen Electoral General, considerando este último incompatible con la condición de concejal a los contratistas o subcontratistas de contratos cuya financiación, total o parcial, corra a cargo de la Corporación Municipal, de establecimientos de ella dependientes. De conformidad con ello, es evidente que la prohibición de contratar no se extiende a los contratos concertados con Administraciones Públicas distintas de aquella a la que pertenece el concejal.

Primer aspecto que, en nuestra opinión, chocaría frontalmente con la nueva previsión comunitaria puesto que, por ejemplo, si un concejal de un partido político concurre a un procedimiento de licitación de una entidad gobernada por miembros del mismo partido, es evidente que no concurrirá en las mismas condiciones que otro licitador que no esté vinculado por su pertenencia a un partido político. Por lo tanto, a nuestro juicio, la normativa faculta un conflicto de intereses que probablemente quede vedado por la nueva regulación comunitaria

El informe 37/2009 de la JCCA de 24 de abril aclaró que sin perjuicio de las incompatibilidades y prohibiciones para contratar que derivan de la aplicación conjunta del artículo 49.1 f) del actual TRLCAP, de la Ley 53/1984, de 26 de diciembre y de la Ley $5 / 1985$, de 19 de junio, los concejales y demás cargos no electos de las Juntas de Gobierno de los Ayuntamientos no están afectados por las limitaciones derivadas de la Ley 5/2006, de 10 de abril, de Regulación de los Conflictos de Intereses de los Miembros del Gobierno y de los Altos Cargos de la Administración General del Estado.

En consecuencia se limita la posibilidad de incluir a los cargos electos municipales en el mismo régimen de incompatibilidades previsto en la Ley 5/2006 ya que la norma en cuestión no los contemplaba en ningún lugar, ni existía precepto legal que sustentara esta previsión. Extremo también criticable en la medida en que es imprescindible que en todos los entes adjudicadores exista, al menos, el mismo régimen de incompatibilidades previsto para la Administración General del Estado. Es más, es que la previsión europea determina medidas para evitar el conflicto de intereses con independencia de cuál sea el ente adjudicador lo que, en la práctica, conllevará el régimen de incompatibilidades más homogéneo del ordenamiento jurídico a efectos de contratación.

También esta prohibición implica que la incompatibilidad que determina prohibición de contratar, sin perjuicio de la que pueda existir para el Alcalde y los Concejales, no existe respecto a las sociedades de las que forman

24 En un principio, una de las dudas que surgió al amparo del artículo 20 TRLCAP fue si las prohibiciones previstas en la parte general del texto normativo resultaban de aplicación al extinto contrato de consultoría y asistencia. Se resolvió reconociendo el carácter vinculante de las prohibiciones de contratación respecto a todos los contratos previstos en las normas de contratación, (incluidos los contratos menores) cualquiera que fuera su modalidad. En este sentido se pronunciaron los Informes de la JCCA 16/02, de 13 de junio, sobre incompatibilidades de funcionarios y sus cónyuges para contratar con la Administración Pública o el Informe 45/01 de 30 de enero de la JCCA, sobre prohibiciones para contratar. 
parte, cualesquiera que sea su participación, salvo para aquellas de las que forman parte, como administradores, los citados cargos electivos ${ }^{25}$.

Se trata de una diferencia fundamental con el régimen aplicable a los funcionarios públicos. Mientras que el cargo electo de la Administración Local no queda limitado en la contratación pública por el hecho de que resulte titular de participaciones sociales de la entidad contratante por encima del 10 por ciento, siempre y cuando no ostente la condición de administrador de la sociedad, en el caso del funcionario público sí queda condicionado por la prohibición en base a la limitación que recoge el artículo 12 de Ley 53/1984, de 26 de diciembre, de Incompatibilidades del Personal al Servicio de las Administraciones Públicas.

Por ello mientras el cargo electo municipal puede participar en la entidad que licita sin ninguna limitación salvo que tenga la condición de administrador de la sociedad, en el caso del funcionario público, éste no puede tener una participación superior al diez por ciento del capital social.

Esta disparidad en el régimen de las prohibiciones, derivada de la normativa de incompatibilidades ha sido duramente criticada por distintos sectores doctrinales que consideran que se trata de una distinción sin fundamento que no beneficia a la transparencia de la contratación pública.

Por ello, y para tratar de solventar esta deficiente regulación el Informe 6/2010, de 23 de julio sobre la aplicación literal del articulo 49.1 f) párrafo segundo la Junta Consultiva de Contratación Administrativa se planteó, ante las diferencias expuestas, si podría hacerse extensiva exclusivamente a los cargos electos municipales el límite de participación en las entidades contratantes del 10\% de su capital social dispuesto en el artículo 5 de la Ley 5/2006, de 10 de abril , de Regulación de los Conflictos de Intereses de los Miembros del Gobierno y de los Altos Cargos de la Administración General del Estado. ${ }^{26}$

Finalmente la Junta Consultiva admitió la necesidad de extender el límite de participación del 10 por ciento en el capital de las entidades que van a contratar de acuerdo con el tratamiento que recoge la prohibición para contratar, partiendo de que entenderlo de forma diferente consagraría un supuesto de desigualdad al tratar de forma diferente dos casos iguales con clara vulneración del artículo 14 de la Constitución Española y, en segundo lugar, porque de conformidad con lo dispuesto en el artículo 4.1 del Código Civil ${ }^{27 .}$

A nuestro juicio, la contraposición de la normativa europea revela la insuficiencia del régimen de incompatibilidades también en este aspecto. Como hemos expuesto, la nueva Directiva fija como límites la existencia de intereses directos o indirectos $y$, evidentemente, tanto si se ostenta un porcentaje u otro de la sociedad que licita se produce un conflicto de interés patente y manifiesto. Una colisión que contraviene literalmente el contenido recogido en su artículo 24.

Por otra parte, resulta pacífico que cuando un concejal sea administrador de una sociedad que pretende contratar con la misma entidad local donde ejerce su representación, opera la prohibición de contratar con el Ayuntamiento de conformidad con el artículo 60 TRLCSP, en relación con el artículo 178 de la Ley Orgánica 5/1985, de 19 de junio de Régimen Electoral General. No obstante, las interpretaciones de los órganos consultivos han permitido que si renuncia a su acta de concejal el mismo día que presenta la propuesta en el procedimiento de licitación, no despliegue sus efectos la prohibición para contratar. ${ }^{28}$

Desde este prisma, tampoco es recomendable permitir esta práctica en la que además de un conflicto manifiesto de intereses, puede concurrir una práctica ilícita en la configuración que ofrece la nueva Directiva de contratación pública al poder generarse una influencia sobre el ente adjudicador. Obsérvese que el artículo 24 de la Directiva específicamente trata de evitar cualquier tipo de interés concurrente no sólo la persona titular del órgano adjudicador sino en todas aquellas personas que puedan intervenir en el procedimiento de licitación.

25 Así lo recoge expresamente el Informe 36/2000 de 30 de octubre de la Junta Consultiva de Contratación Administrativa sobre incompatibilidades de los concejales.

26 Obsérvese en esta materia que las distintas CCAA han promulgado normas sobre incompatibilidades de los miembros del Gobierno Autonómico y de los Altos cargos de la Administración Autonómica que deben tenerse en cuenta a la hora de valorar esta prohibición para contratar. En concreto, se pueden citar: la Ley 2/1996, de 2 de noviembre, de Incompatibilidades de Altos Cargos de las Islas Baleares; Ley 1/2008, de 2 de julio, de Conflicto de Intereses de los miembros del Gobierno y Altos Cargos de Cantabria; la Ley 19/1996, de 4 de noviembre, de Incompatibilidades de miembros del Gobierno y Altos Cargos de la Comunidad Foral de Navarra; Ley 13/2005, de 27 de diciembre, de Incompatibilidades de Altos Cargos de Cataluña; Ley 8/2003, de 28 de octubre, Reguladora del Gobierno de las Incompatibilidades de sus Altos Cargos; Ley 5/1985, de 3 de junio, Incompatibilidades de miembros del Gobierno y Altos Cargos; Ley 3/2005, de 8 de abril, de Incompatibilidades de Altos Cargos de la Administración Andaluza.

27 A la misma conclusión llega la Junta Consultiva de Contratación Administrativa de Aragón en su Informe 24/2011, de 12 de septiembre sobre las prohibiciones de contratar con personas jurídicas en cuyo capital social participen miembros de la Corporación Local.

28 En este sentido se pronuncia la Sentencia del Tribunal Superior de Justicia de Cataluña de 9 de junio de 2006 (RJ 2006,295943 ) que no considera que concurra causa de nulidad. 
La prohibición de contratar por causa de incompatibilidad de un funcionario debe limitarse exclusivamente a la Administración Pública contratante, a la que pertenezca el funcionario tal y como dictamino la JCCA en su Informe 16/2002, de 13 de junio en relación con las incompatibilidades de los funcionarios públicos.

En este sentido las circunstancias que ocasionan la incompatibilidad de los funcionarios y que pueden tornarse en causas de prohibición con arreglo al artículo 12 de la Ley 53/1984 son: A) la pertenencia a consejos de administración u órganos rectores de empresas o entidades privadas, siempre que la actividad de las mismas esté directamente relacionada con las que gestione el departamento, organismo o entidad en que preste sus servicios el personal afectado B) El desempeño, por sí o persona interpuesta, de cargos de todo orden en empresas o sociedades concesionarias, contratistas de obras, servicios o suministros, arrendatarias o administradoras de monopolios, o con participación o aval del sector público, cualquiera que sea la configuración jurídica de aquéllas. C) La participación superior al 10 por 100 en el capital de las empresas o sociedades a que se refiere el párrafo anterior. Estas circunstancias son predicables también en cuanto a la contratación pública del cónyuge o personas vinculadas con análoga relación de convivencia afectiva y descendientes de las personas a que se refieren los párrafos anteriores, siempre que, respecto de los últimos, dichas personas ostenten su representación legal, de acuerdo con el párrafo segundo del artículo 60 TRLCSP.

A este respecto, con la versión definitiva de la nueva Directiva de Contratos, también resulta necesario deslindar perfectamente los conflictos de interés que puedan producirse ya que, a nuestro juicio, las incompatibilidades de funcionarios permiten un ángulo de exención que puede facilitar prácticas corruptas.

\section{Desempeño de servicios en empresas privadas relacionadas con el cargo}

El artículo 60.1 apartado g) del TRLCSP contempla como prohibición para contratar:

“g) Haber contratado a personas respecto de las que se haya publicado en el «Boletín Oficial del Estado» el incumplimiento a que se refiere el artículo 18.6 de la Ley 5/2006, de 10 de abril, de Regulación de los Conflictos de Intereses de los Miembros del Gobierno y de los Altos Cargos de la Administración General del Estado, por haber pasado a prestar servicios en empresas o sociedades privadas directamente relacionadas con las competencias del cargo desempeñado durante los dos años siguientes a la fecha de cese en el mismo. La prohibición de contratar se mantendrá durante el tiempo que permanezca dentro de la organización de la empresa la persona contratada con el límite máximo de dos años a contar desde el cese como alto cargo."

Esta circunstancia es una de las novedades que incorporó el TRLCSP con un resultado estéril ${ }^{29}$. Se diseñó para evitar que aquellos que han ostentado un cargo de relevancia en la Administración General del Estado puedan beneficiarse de su experiencia y generen un conflicto de intereses cuando, finalizado su cargo, se encuentren en el sector privado. Se persigue, por tanto, que determinadas personas durante su mandato o tras su cese, no utilicen indebidamente las influencias derivadas de su experiencia en el Gobierno o la Administración Pública una vez que ya se encuentran en el ámbito privado. Pese a ello su eficacia ha sido muy limitada y la colisión de intereses se ha trasladado incluso a las relaciones entre entes reguladores y entidades reguladas, en lo que supone una evolución en el comportamiento éticamente censurable. ${ }^{30}$

Realmente con la configuración de este supuesto se produce, de nuevo, la discordancia de esta previsión normativa con el resto de disposiciones que son de aplicación al resto de Administraciones Públicas. Ello porque, esta previsión, es predicable exclusivamente para los Altos Cargos de la Administración General del Estado sin que la normativa contractual, incorpore, como sería deseable una previsión equivalente para el resto de Administraciones Públicas.

Es cierto que este aspecto, y parte de las limitaciones de la Ley 5/2006 de 10 de abril, de Regulación de los Conflictos de Intereses de los Miembros del Gobierno y de los Altos Cargos de la Administración General del Estado, se extendieron al ámbito local ${ }^{11}$ y que en el caso de las Administraciones Autonómicas, algunas CCAA han dictado

29 Sin retroceder mucho en el tiempo, una visión de la trayectoria de las personas que han ostentado la condición de Ministros en las dos últimas legislaturas revela que la mayoría actualmente mantienen una vinculación con entidades ubicadas en el sector donde desempeñaron sus funciones. Dato que revela que la limitación temporal que fija la norma no es una prohibición sino una condición procedimental, fija el periodo que el político debe estar sin una vinculación aparente para poder formalizarla tras los dos años siguientes a cese del cargo.

30 Como ejemplos significativos podemos citar la polémica candidatura del ex Director General del Banco de España a presidir la Asociación Española de la Banca (AEB) o el nombramiento del Director de la Oficina Económica del Gobierno como presidente de la Patronal de las Constructoras (SEOPAN).

31 El Real Decreto Legislativo 2/2008, de 20 de junio, por el que se aprobó el Texto Refundido de la ley del suelo introdujo en la Disposición Adicional Novena una modificación de la la Ley 7/1985, de 2 de abril, Reguladora de las Bases del Régimen Local respecto a las incompatibilidades de los titulares de órganos directivos locales sujetándola a lo establecido en la Ley 53/1984, de 26 de diciembre. Igualmente estableció, únicamente, la limitación de dos años prevista en el artículo 8 de la Ley 5/2006 de 10 de abril e incorporó la obligación de que los representantes locales, los directivos y los funcionarios de especial responsabilidad declarasen sobre posibles causas de incompatibilidad y 
normas equivalentes en el ejercicio de sus competencias sobre la incompatibilidad de Altos Cargos del Gobierno Autonómico ${ }^{32}$, no obstante, a nuestro juicio, es necesario un régimen básico y uniforme en relación a esta cuestión.

Por otra parte, en una sociedad tan dinámica como la actual donde los puestos directivos están vinculados generalmente con el partido político imperante y la mayoría de puestos de libre designación en el seno de la Administración Pública suelen tener un carácter transitorio, es necesario que se respeten los intereses concurrentes y que los conflictos de interés sean salvaguardados no sólo durante el ejercicio del cargo sino también posteriormente cuando el Alto Cargo ya ha cesado en su actividad, siendo el límite de dos años, un obstáculo testimonial tal y como se ha acreditado en la práctica.

\section{$2^{\text {a }}$ DISTORSIÓN: LAS CONDICIONES DE COMPATIBILIDAD}

El articulo 56 TRLCSP señala que salvo los casos de dialogo competitivo, no podrán concurrir a las licitaciones empresas que hubieran participado en la elaboración de las especificaciones técnicas o de los documentos preparatorios del contrato siempre que dicha participación pueda provocar restricciones a la libre concurrencia o suponer un trato privilegiado con respecto al resto de las empresas licitadoras. En el caso de los contratos que tengan por objeto la vigilancia, supervisión, control y dirección de la ejecución de obras e instalaciones, la Ley establece además, que no podrán adjudicarse a las mismas empresas adjudicatarias de los correspondientes contratos de obras, ni a las empresas a éstas vinculadas, entendiéndose por tales las que se encuentren en alguno de los supuestos previstos en el artículo 42 del Código de Comercio.

A nuestro juicio esta disposición sobre el procedimiento de contratación debiera perfilarse a la luz de las nuevas medidas para la integridad expuestas anteriormente. Sería conveniente que se erradicara la posibilidad de intereses indirectos de las entidades que participan en la elaboración de especificaciones técnicas y que expresamente contemplara el contenido de las medidas ilícitas plasmadas en la propuesta comunitaria. Es necesario determinar si las normas sobre contratación van a ser disposiciones vacías de contenido o si, tras el previsible mandato comunitario, pretendemos hacer controles férreos y efectivos. ${ }^{33}$ Fundamentalmente porque, como hemos apuntado, si los presupuestos de hecho de las normas sobre integridad en la contratación pública van a depender de condiciones difíciles de acreditar se limita la eficacia de las garantías de contratación pública y se conculca la presunción de partida que debe ser la eliminación de cualquier eventual conflicto de interés, salvo que se pruebe lo contrario.

Por ello, tras la redacción de las conductas ilícitas en el procedimiento de contratación es necesario que las condiciones de compatibilidad recojan al menos todas las conductas vetadas por la normativa comunitaria.

\section{$3^{\mathrm{a}}$ DISTORSIÓN: CAUSAS DE ABSTENCIÖN DEL ARTÍCULO 28 LRJAP Y 52 EBEP}

Cabe plantearse cuál sería la relación entre el tratamiento del conflicto de interés que recoge la norma comunitaria y las causas de abstención y recusación, aplicables a autoridades y funcionarios, previstas en el artículo 28 de la Ley 30/1992, de 26 de noviembre, Ley de Régimen Jurídico de las Administraciones Públicas y Procedimiento Administrativo Común y en el artículo 52 del Estatuto Básico del Empleado Público, aprobado mediante la Ley $7 / 2007$, de 12 de abril.

Según la doctrina la previsión de la normativa europea debe suponer un régimen de abstención y recusación más ambicioso en la contratación pública que en el resto de la actividad administrativa. ${ }^{34}$ Debiera conllevar un

sobre sus bienes y actividades.

32 Además respecto a la prohibición del apartado g) del artículo 49 de la LCSP, el Dictamen del Consejo de Estado de 25 de mayo de 2006, sobre el Anteproyecto de la Ley de Contratos del Sector Público, sugirió la posibilidad de ampliar la limitación a las personas cercanas al sujeto que ha dejado de ser Alto Cargo de la Administración Pública. Esta propuesta era consciente de la necesidad de delimitar perfectamente los supuestos de incompatibilidad en estas ocasiones. Finalmente el texto legal mantuvo su redacción originaria.

33 El Informe 9/2010, de 15 de septiembre de la Junta Consultiva de Contratación Administrativa de la Comunidad de Aragón examina la posibilidad de que la empresa redactora de un proyecto pueda presentar ofertas en el procedimiento de contratación de la dirección de obras. Concluye señalando que en un procedimiento de contratación de servicios de dirección de obras puede presentar proposición y en su caso resultar adjudicatario el empresario redactor del proyecto, sin que sea de aplicación en este caso la prohibición del articulo 56.1 LCSP, ya que las especificaciones técnicas y los documentos preparatorios del futuro contrato de dirección facultativa no son las contenidas en el proyecto de obras, sino otra diferentes, que corresponden a un contrato distinto y que definirán las características del servicio que deberá prestar el facultativo adjudicatario permitiendo caracterizarlo objetivamente. Además señala, en contra de nuestras tesis, que la redacción previa de un proyecto no supone en sí misma un clara discriminación positiva respecto del resto de futuros licitadores a la dirección de la obra, sin que quepa impedir el acceso a la licitación a quien no quede suficientemente demostrado que cuente con ventaja respecto a sus competidores. Esta exclusión solamente será posible si, como indica el articulo 56.1 TRLCSP “dicha participación pueda provocar restricciones a la libre concurrencia o suponer un trato privilegiado con el resto de empresas licitadoras.

34 GIMENO FELIÚ, J.M. “Las nuevas directivas -cuarta generación- en materia de contratación pública. Hacia una estrategia eficiente en compra pública” Revista Española de Derecho Administrativo, número 159, 2013, página 70. 
régimen cualificado donde los agentes que puedan intervenir en el procedimiento de licitación garanticen un ámbito de imparcialidad evitando cualquier eventual situación de conflicto. En consecuencia, sería una norma especial, con un presupuesto de hecho más amplio, aplicable a todos los entes, organismos y entidades del sector público, cualquiera que sea su naturaleza, y, además, más garantista que los preceptos mencionados.

\section{$4^{a}$ DISTORSIÓN: LAS PREVISIONES NORMATIVAS SOBRE TRANSPARENCIA Y BUEN GOBIERNO EN RELACIÓN A LA CONTRATACIÓN PÚBLICA}

En la contraposición normativa, era imprescindible examinar las incipientes y novedosas normas sobre transparencia y buen gobierno que han proliferado como el elemento de moda contra la corrupción. Los resultados no son los deseados en relación con las medidas de integridad que requiere la contratación pública.

La reciente Ley 19/2013, de 9 de diciembre, de Transparencia, Acceso a la Información Pública y Buen Gobierno mantiene el mismo régimen de incompatibilidades anteriormente comentado y resulta bastante limitado en relación a la contratación pública, pese a ser el cauce normal de conductas irregulares. Como pone de relieve BARRERO RODRíGUEZ, el núcleo de la norma se centra en el derecho de acceso a la información como pilar fundamental de la actuación púbica transparente 35 .

En consecuencia la célebre nueva disposición mantiene el mismo régimen de incompatibilidades con que hemos comentado con la misma limitación temporal y sin ninguna aportación sustancial que garantice ámbitos de imparcialidad como elemento imprescindible para lograr el gobierno que pretende garantizar la Ley. ${ }^{36}$

Tampoco el Proyecto de Ley de Transparencia Pública en Andalucía contiene mención alguna a las normas de integridad en el régimen de contratación ${ }^{37}$. Al igual que otras disposiciones autonómicas se articula como una norma sobre publicidad e información de la actividad de los poderes públicos, sin realizar ninguna modificación o ampliación del ámbito de aplicación de la Ley 8/2005 de 8 de abril, de Incompatibilidades de Altos Cargos de la Administración de la Junta de Andalucía y Declaración de Actividades, Bienes e Intereses y Retribuciones de Altos Cargos y Otros Cargos Públicos.

Ahondando en esta reflexión, los avances en la materia de contratación pública deben suponer un diseño más exigente del régimen de incompatibilidades incorporado de forma que impida que personas que ostenten esta condición puedan participar como accionistas o a través de personas vinculadas en procedimientos de licitación de la Administración Autonómica..$^{38}$ Es evidente que en el ámbito europeo se pretende evitar las situaciones de conflicto de interés, como un concepto más amplio que el régimen de incompatibilidad. Como un parámetro más exigente a la hora de calificar la moralidad administrativa y por ello, las disposiciones en relación a las causas de incompatibilidad, al régimen de contratación y, sobre todo, al buen gobierno deben perfilar las normas de tal manera que se cierren espacios que permitían eventuales conflictos de interés manifiestos y ostensibles.

El repaso al resto de disposiciones similares conduce a resultados parecidos. La Ley 4/2006, de 30 de junio, de Transparencia y Buenas Prácticas de la Administración Pública Gallega no aborda los eventuales conflictos de interés en la contratación pública. Sólo el Anteproyecto de Ley de Transparencia Pública de Andalucía, aprobada por el Consejo de Gobierno el 4 de junio de 2013 y la Ley 4/2011, de 31 de marzo, de la Buena Administración y del Buen Gobierno de Illes Baleares, se refieren a esta cuestión. Ésta última, en concreto, se centra en esta cuestión en los artículos 34 a 36, en lo que supone un avance sustancial en la materia39.

35 BARRERo RodríGUeZ, c. “ La Disposición Adicional 1.3 del Proyecto de Ley de Transparencia, Acceso a la Información y Buen Gobierno y sus negativos efectos en el ámbito de aplicación del derecho de acceso a la información”, Revista Española de Derecho Administrativo número $158 / 2013$ pagina 26.

36 El artículo 27 de la Ley es el que se encarga de las incompatibilidades y la disposición final segunda es la que modifica la denominación de la "Oficina de Conflictos e Interés" a "Oficina de Buen Gobierno y Conflictos de Interés".

37 El Proyecto sí recoge disposiciones ambiciosas respecto a publicidad e información en el régimen de contratación. Novedoso resulta el artículo 15 del proyecto respecto a la información sobre contratos, convenios y subvenciones y, sobre todo, la Disposición Adicional Séptima del Proyecto, relativa a la transparencia en los procedimientos negociados sin publicidad. Se trata de una medida realmente novedosa que obliga a que las personas y entidades incluidas en su ámbito de aplicación a publicar en su perfil del contratante simultáneamente al envío de las solicitudes de ofertas a las que se refiere el artículo 178.1.TRLCSP, un anuncio, al objeto de facilitar la participación de otros posibles licitadores. Las ofertas que presenten los licitadores que no hayan sido invitados no podrán rechazarse exclusivamente por dicha circunstancia.

38 El artículo 9 de la Ley 8/2005, de 8 de abril, de Incompatibilidades de Altos Cargos de la Administración de la Junta de Andalucía y Declaración de Actividades, Bienes e Intereses y Retribuciones de Altos Cargos y Otros Cargos solamente exige que se acredite, mediante la oportuna certificación expedida por su órgano de dirección o representación competente, que no forma parte de los órganos de gobierno o administración, lo que en la práctica supone un espacio de dispensa donde pueden existir conflictos manifiestos de intereses al permitir situaciones de participación en sociedades como accionistas o a través de personas interpuestas.

39 El artículo 36 de la Ley 4/2011, de 31 de marzo, de Buena Administración y de Buen Gobierno de Illes Baleares obliga a los Altos Cargos a abstenerse o inhibirse en aquellas decisiones que puedan afectar a sus intereses o los de persona con parentesco hasta segundo grado de afinidad. 
En definitiva, si los avances europeos en materia de contratación pública pretenden elevar el nivel de moralidad administrativa exigiendo a los Estados miembros que detecten y solucionen los eventuales conflictos de interés que puedan concurrir, es lógico, que las incipientes normas sobre transparencia y buen gobierno, sobre todo en relación a este último objetivo, acompañen las disposiciones con medidas que garanticen la integridad en la contratación pública, como una parte esencial de la actividad de gobierno.

\section{CONCLUSIONES}

$1^{\circ}$.- La nueva Directiva de Contratación Pública, la Directiva 2014/24/UE del Parlamento Europeo y del Consejo, de 26 de febrero de 2014, sobre contratación pública, introduce novedades en relación con la integridad en el procedimiento de contratación que pretenden, entre otros objetivos, evitar las prácticas deshonestas y el favoritismo en la contratación pública. La interdicción de los conflictos de interés prevista en el artículo 24, es la determinación normativa fundamental que los Estado miembros deben integrar de forma efectiva y útil en su normativa de contratación pública.

En el ordenamiento jurídico español, la aprobación de la nueva Directiva, debe conllevar, necesariamente, elevar la maltrecha moralidad administrativa en la contratación pública española perfilando disposiciones y adoptando medidas complementarias que aseguren espacios de imparcialidad y objetividad para lograr la consecución del interés general.

$2^{\circ}$.- La relación Derecho de la Unión Europea-normativa interna española revela la necesidad de perfeccionar determinadas disposiciones para evitar eventuales conflictos de interés debido a la fragmentación normativa, la dispersión de entes adjudicadores y la inexistencia de controles necesarios. Concretamente, para cumplir con el Derecho Comunitario, es imprescindible un nuevo diseño de los apartados f) y g) del artículo 60 TRLCSP relativo a las prohibiciones para contratar; es inaplazable fijar un régimen de incompatibilidades homogéneo para todos los poderes adjudicadores y también es conveniente establecer más medidas para garantizar que no se produzcan conductas ilícitas en la contratación pública ${ }^{40}$.

Igualmente sería deseable que las incipientes normas sobre transparencia y buen gobierno incorporaran medidas en este ámbito que, sorprendentemente, ha quedado olvidado en el texto de estas disposiciones, ya que la eliminación de situaciones que puedan incidir sobre la imparcialidad o el establecimiento de controles para evitar la concurrencia de inclinaciones, son elementos imprescindibles para servir con objetividad a los intereses generales, a tenor del artículo 103 CE.

$3^{\circ}$.- Como colofón a todo lo anterior, entendemos que las nuevas medidas sobre integridad en la contratación pública que se impulsan desde Europa deben servir para que en el ordenamiento español se completen correctamente las disposiciones existentes, aprovechando la coyuntura para elevar el nivel de moralidad administrativa, trasladando el parámetro de exigencia desde la prohibición y la incompatibilidad hasta el conflicto de interés, como medida para garantizar ámbitos de objetividad donde no puedan colisionar intereses concurrentes. Sería conveniente para ello, articular medidas homogéneas y uniformes para todos los entes adjudicadores con la finalidad de inspeccionar y controlar estas situaciones y lograr combatir, de una vez por todas, las complejas prácticas deshonestas. ${ }^{41}$

\section{BIBLIOGRAFÍA}

- Alvarez mARTín, J.A. “La futura ley de transparencia ¿una solución adecuada y creíble?” Revista Aranzadi Doctrinal número 7/2012.

- barrero rodrícuez, C. "La Disposición Adicional 1. $3^{\circ}$ del Proyecto de Ley de Transparencia, Acceso a la Información y Buen Gobierno y sus negativos efectos en el ámbito de aplicación del derecho de acceso a la información" Revista Española de Derecho Administrativo número 158/2013.

- BESTEIRO RIVAS, DE J. “Comentario al artículo 49 LCSP: Las Prohibiciones de contratar”, edit. Aranzadi, Pamplona 2009.

- DE LA SIERRA MORÓN, S, “Un legislador impenitente: Derecho de la Unión y procedimiento de contratación

40 Cumplir con Europa en este ámbito no ha sido, precisamente, una especialidad del Estado Español. Como señala de la sierra, en su trabajo “Un legislador impenitente: Derecho de la Unión y procedimiento de contratación pública" Revista española de Derecho Administrativo número 149, página 1, si existe un ámbito del Derecho en el que el legislador español ha sido especialmente contumaz y persistente en el incumplimiento de Derecho comunitario, ese ámbito es la contratación pública.

41 Sobre las medidas para garantizar la integridad en la contratación resulta muy ilustrativo el estudio de GIMENO FELIU, J.M, “La Ley de Contratos del Sector Público: ¿una herramienta eficaz para garantizar la integridad?.Mecanismos de control de la corrupción en la contratación pública" Revista Española de Derecho Administrativo, número 147, páginas 517 a 535. 
pública" Revista española de Derecho Administrativo número 149.

- GALlego CórColes I. "Prohibiciones de contratar: el régimen de incompatibilidades (I)" Contratación Administrativa Práctica: Revista de la Contratación Administrativa y de los Contratistas nº 40/2005, edit. La Ley, Madrid, 2005.

- GAllego CórColes I "Prohibiciones de contratar. El régimen de incompatibilidades (II)" Contratación Administrativa Práctica: Revista de la Contratación Administrativa y de los Contratistas n 41/2005, edit. La Ley, Madrid, 2005

- Garcia tORRES, A. "Transparencia.-Acceso a la Información Pública.-Buen Gobierno. Proyecto de Ley de Transparencia, Acceso a la Información Pública y buen Gobierno" La Administración Práctica número 9/2012.

- GIMENO FELIÚ, J.M. "Las nuevas directivas -cuarta generación- en materia de contratación pública. Hacia una estrategia eficiente en compra pública” Revista Española de Derecho Administrativo, número 159.

- Gimeno feliú, J.m "La Ley de Contratos del Sector Público: ¿una herramienta eficaz para garantizar la integridad?.Mecanismos de control de la corrupción en la contratación pública" Revista Española de Derecho Administrativo, número 147.

- GONZÁLEZ ALONSO, A "Los principios del derecho administrativo comunitario" Revista Aranzadi de la Unión Europea 6/2011.

- Guajardo Perez, I "Afiliación política de los Magistrados del Tribunal Constitucional. Inadmisión de la recusación promovida contra su Presidente por el parlamento y la Generalidad de Cataluña (artículo 219 LOPJ nums. 9 y 10)" Diario La Ley, n 8198, 25 de noviembre de 2013.

- J.A. MOLINA "Un mundo para SARA, una nueva categoría en el Derecho español de la contratación pública, los contratos sujetos a regulación armonizada" Revista de Administración Pública, número 178, 2009.

- Medina ARnalz T.”Las respuestas normativas al fenómeno de la corrupción en la contratación pública”, Diario La Ley número 7832, sección doctrina, de 16 de abril de 2010

- SANTAMARIA PASTOR, J.A. "La constante e interminable reforma de la normativa sobre contratación pública" Revista Española de Derecho Administrativo, número 159. 